\title{
Physically Connected Stacked Patch Antenna Design with $100 \%$ Bandwidth
}

\author{
Kirill Klionovski and Atif Shamim, Senior Member, IEEE
}

\begin{abstract}
Typically, stacked patch antennas are parasitically coupled and provide larger bandwidth than a single patch antenna. Here, we show a stacked patch antenna design where square patches with semi-circular cutouts are physically connected to each other. This arrangement provides $100 \%$ bandwidth from 23.9-72.2 GHz with consistent high gain (5 dBi or more) across the entire bandwidth. In another variation, a single patch loaded with a superstrate provides $83.5 \%$ bandwidth from 25.6-62.3 GHz. The mechanism of bandwidth enhancement is explained through electromagnetic simulations. Measured reflection coefficient, radiation patterns and gain results confirm the extremely wideband performance of the design.
\end{abstract}

Index Terms-Wideband patch antenna, dielectric superstrate, stacked patch antenna.

\section{INTRODUCTION}

$\mathrm{N}$ EW wireless telecommunication technologies are moving to millimeter-wave bands and require very wideband antennas to cater to next-generation high-data-rate applications. Therefore, the future $5 \mathrm{G}$ Local Multipoint Distribution Service (LMDS) band is promising to operate in the $27.5-31.3 \mathrm{GHz}$ band [1]. The next-generation wireless local area network (WLAN) and wireless personal area network (WPAN) will exploit the $60 \mathrm{GHz}$ spectrum [2]. Among a wide variety of ultrawideband antennas [3], broadband patch antennas are attractive for telecommunication systems as they have omnidirectional radiation patterns.

Many designs of broadband patch antennas have been reported in literature [4-16]. Stacked patch antennas with bandwidths (BWs) up to $20 \%$ are reported in [4]. In references [12] and [16], a stacked patch antenna design has been introduced which demonstrates a maximum BW of $27 \%$. This design employs angled circular cutouts in square metallic radiating elements to achieve a wide BW. However, the central pin of the coaxial cable has electric contact only with the bottom patch. In another design, a U-slot microstrip antenna with an Eshaped stacked patch achieves an impedance BW of 59.7\% [7], while a rectangular stacked patch antenna with a dielectric superstrate demonstrates a BW of $69 \%$ [5]. In [8], a rose leafshaped microstrip antenna with a capacitively coupled rectangular feed shows an impedance BW of about $69 \%$, while in [10], a broadband L-strip-fed printed microstrip antenna

This publication is based upon work supported by the King Abdullah University of Science and Technology (KAUST) Office of Sponsored Research (OSR) under Award No. OSR-2016-KKI-2899. achieves a BW of $74 \%$. A probe-fed stacked square patch slotted wideband microstrip antenna with an impedance BW of $76.25 \%$ is presented in [6]. The design in [6] has misaligned square slotted patches with shorting walls. A stacked patch antenna with a folded patch feed and a BW of $90 \%$ is presented in [9]. This strip-loaded slotted microstrip antenna is fed by an L-strip feed line to achieve impedance matching for the higherorder modes of the patch antenna in addition to the existing resonances. A design for a probe-fed shorted asymmetric Eshaped patch antenna with $110 \% \mathrm{BW}$ is presented in [11]. A $112 \%$ BW square patch antenna with four capacitively coupled feeds is presented in [13]. In references [14] and [15], metamaterial-based patch antennas with $129 \%$ and $134 \%$ BWs are presented.

From the above literature review, we can see that patch antenna designs from [11, 13-15] have impedance BWs of more than $100 \%$. However, the issue with these designs is that they do not provide consistent high gain across the band, and at some frequency points, their gains drop below $2 \mathrm{dBi}$. This means that the real working BWs of these designs are less than $100 \%$. To overcome this issue, we present a stacked patch antenna design where the stacked patches are physically connected through the coaxial cable pin (instead of the typical capacitive coupling). By virtue of this approach, to the authors' best knowledge, this design for the first time provides a consistent gain of $5 \mathrm{dBi}$ or more across the entire $100 \% \mathrm{BW}$.

\section{Design of A Single Patch ANTENNA ELEMENT WITH A SUPERSTRATE}

Let us consider a single-element patch antenna with a metallic radiating element in the form of a square plate of length $L_{1}=$ $2.65 \mathrm{~mm}$ that has angled circular cutouts of radii $R_{l}=0.95 \mathrm{~mm}$ (Fig. 1) [17]. The radiating element is implemented on a Rogers RO4533 substrate, which has a permittivity of 3.3, loss tangent of 0.0025 , thickness of $0.76 \mathrm{~mm}$, and a radius of $5 \mathrm{~mm}$. The bottom side of the substrate is metallized and thus acts as the ground plane for the patch antenna. The patch was excited by a $50-\Omega$ coaxial cable, which was located at a distance of $0.78 \mathrm{~mm}$ from the center of the patch (along the $\mathrm{X}$-axis). The outer ground of the coaxial cable has been connected to the patch ground plane.

Let us investigate the influence of the diameter $d$ of the central

The authors are with King Abdullah University of Science and Technology (KAUST), Thuwal, 23955-6900, Kingdom of Saudi Arabia (e-mail: kirill.klionovski@kaust.edu.sa, atif.shamim@kaust.edu.sa). 


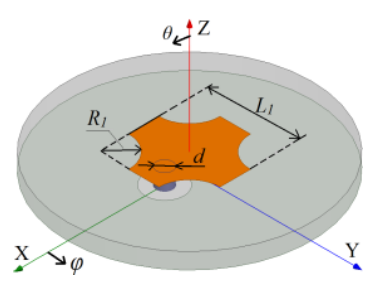

Fig. 1. A single element patch antenna.

pin of the feeding coaxial cable on the reflection coefficient $\left(\mathrm{S}_{11}\right)$ of the patch antenna. As we can see further, for the considered shape of the radiating patch, $d$ had a strong effect on $\mathrm{S}_{11}$. The diameter varied from 0.1 to $0.5 \mathrm{~mm}$. The outer diameter of the coaxial connector was varied proportionally to $d$ in simulations to obtain a $50-\Omega$ wave impedance. A singleelement patch antenna was simulated using Ansoft HFSS software for the dimensions mentioned above. Fig. 2 plots the simulated $\mathrm{S}_{11}$ of the single-element patch antenna. From this

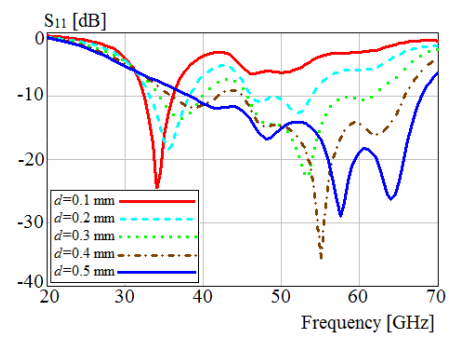

Fig. 2. $\mathrm{S}_{11}$ of the patch antenna with various values of $d$.

figure, we can see that for the thin pin of the coaxial cable, the patch antenna only had a single resonance at the frequency of $34 \mathrm{GHz}$ with a BW of $10 \%$. The resonance shifted to higher frequencies and the $\mathrm{BW}$ increased when the diameter of the coaxial cables increased. When $d=0.5 \mathrm{~mm}, \mathrm{~S}_{11}$ was less than $10 \mathrm{~dB}$ for the frequencies of $39-68 \mathrm{GHz}$ and had four resonances at frequencies of 42, 48, 58 and $64 \mathrm{GHz}$.

One of the methods to increase the gain, efficiency and BW of a patch antenna is the use of superstrates [18]. The effect of $\mathrm{BW}$ increase and change of resonance frequency of a square patch antenna has been studied for metamaterial superstrates $[19,20]$ and dielectric superstrates $[5,21]$. To improve the BW of the single-element patch antenna with $d=0.5 \mathrm{~mm}$, we covered the antenna with a dielectric superstrate, which was based on a Rogers RO4533 substrate with radius of $5 \mathrm{~mm}$ and thickness $t$. Fig. 3 shows the simulated $\mathrm{S}_{11}$ of the patch antenna without the superstrate and with a dielectric superstrate with varying thicknesses of $0.3,0.6,0.76$ and $0.9 \mathrm{~mm}$. From this figure we can see that the dielectric superstrate changed the frequency of each of the resonances of the single-element patch antenna. The widest working frequency band of $26.4-62 \mathrm{GHz}$ (the $\mathrm{BW}$ is $80.5 \%$ ) was obtained when $t=0.76 \mathrm{~mm}$.

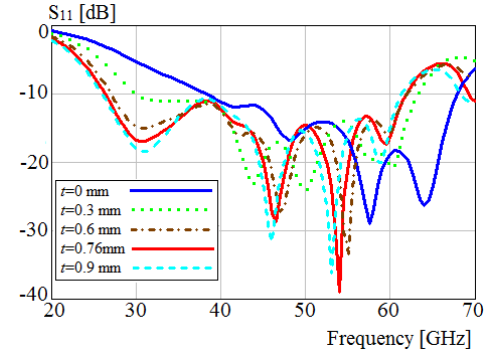

Fig. 3. $\mathrm{S}_{11}$ of the patch antenna with various values of $t$.
A single-element patch antenna with the dimensions described above and a dielectric superstrate with $t=0.76 \mathrm{~mm}$ was fabricated and measured (Fig. 4). As a feed connector, we used a standard 50- $\Omega$ SMA (manufacturer: Amphenol SV Microwave, part number: 3321-60001).

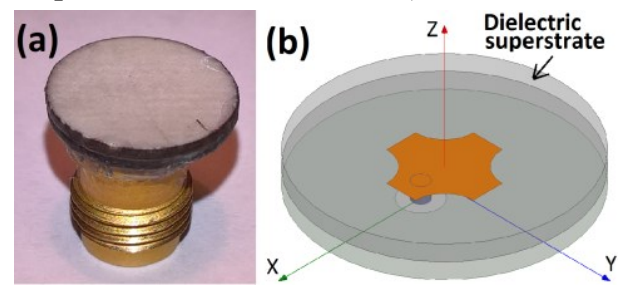

Fig. 4. (a) A photo of the fabricated single element patch antenna with dielectric superstrate and (b) a view of the patch antenna with dielectric superstrate.

Fig. 5 plots the measured and simulated $S_{11}$ of the patch antenna with a dielectric superstrate. From this figure we can see that the measured $S_{11}$ of the patch antenna was less than -10 $\mathrm{dB}$ for the frequencies 25.6-62.3 GHz (the BW was 83.5\%). The broadband operational mode was provided by four resonances, which corresponded to measured (simulated) frequencies of 28 (31), 44 (46), 52 (54) and 58 (59) GHz.

Fig. 6 plots the measured and simulated meridional $\left(E_{\theta}\right)$ and

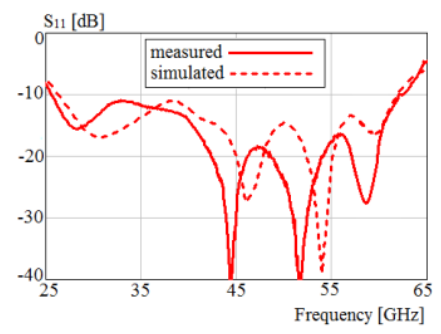

Fig. 5. $\mathrm{S}_{11}$ of the patch antenna with dielectric superstrate.

azimuthal $\left(E_{\varphi}\right)$ components of the radiation patterns and peak gain of the patch antenna with the dielectric superstrate. The angle $\theta$ in the figure was measured from the $\mathrm{Z}$-axis.

From Fig. 6, we can see that the radiation patterns have an asymmetrical shape in the XZ-plane, which was due to the
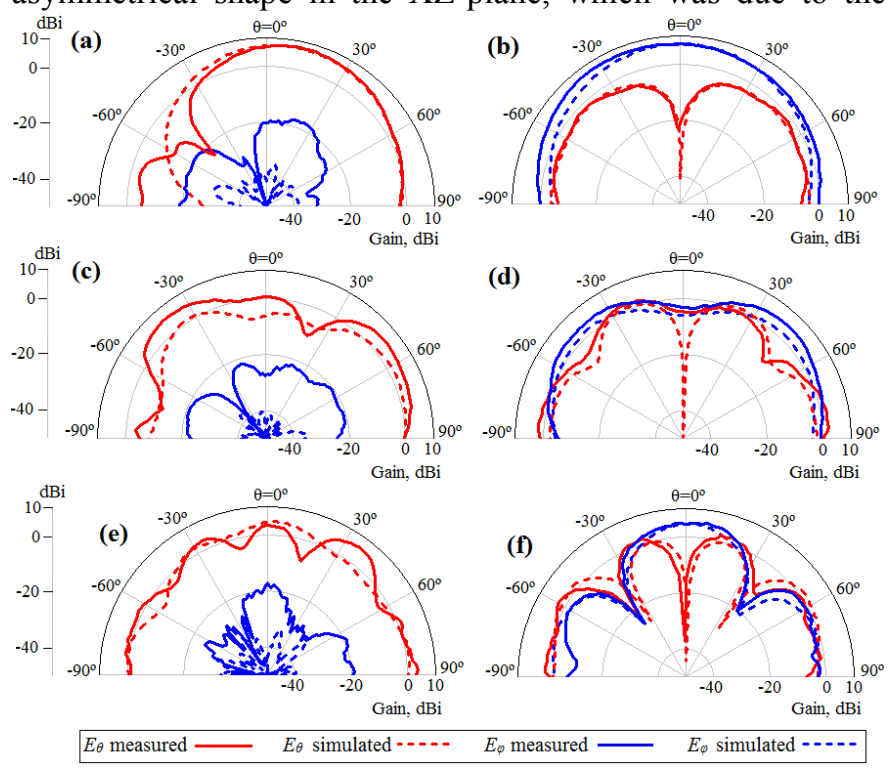

Fig. 6. Radiation patterns of the patch antenna with dielectric superstrate: (a) XZ-plane, $30 \mathrm{GHz}$; (b) YZ-plane, $30 \mathrm{GHz}$; (c) XZ-plane, $45 \mathrm{GHz}$; (d) YZplane, $45 \mathrm{GHz}$; (e) XZ-plane, $60 \mathrm{GHz}$; (f) YZ-plane, $60 \mathrm{GHz}$. 
excitation of the patch by the coaxial cable with a thick pin. Generally, there is a good agreement between the simulated and measured radiation patterns, but the slight differences can be due to the influence of the feeding cable used in the measurements. It was expected to see a null for $E_{\theta}$ in the Z-axis direction and a symmetrical shape for $E_{\theta}$ and $E_{\varphi}$ in the YZplane, as this is the trend for the radiation patterns for $\mathrm{TM}_{20}$ and $\mathrm{TM}_{21}$ modes of a circular patch antenna [4], which is quite close to our proposed antenna geometry as well. It can be clearly seen in Fig. 7 that the measured peak gain (the peak gain is the maximum gain over all the directions of the far-field infinite sphere) and the simulated total efficiency varies from 5.1 to 7.8 $\mathrm{dBi}$ (a variation of less than $3 \mathrm{~dB}$ ) and from 0.66 to 0.94 respectively for the entire working frequency band. The lower measured gain value $(\sim 5 \mathrm{dBi})$ around $40-50 \mathrm{GHz}$ band is due to the relatively lower directivity of the antenna from the resonant modes excited in this band as compared to relatively higher gain values $(\sim 7.5 \mathrm{dBi})$ for other bands.

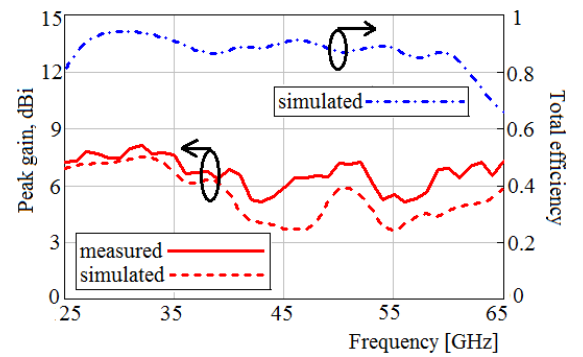

Fig. 7. Peak gain and total efficiency of the patch antenna with dielectric superstrate.

\section{The Modified Stacked Patch Antenna Design}

The next improvement for the $\mathrm{BW}$ of the single patch antenna with dielectric superstrate was made possible by the creation of an additional fifth resonance. The additional resonance could be obtained by increasing the length of the central pin of the coaxial cable to the thickness of the superstrate (Fig. 8).

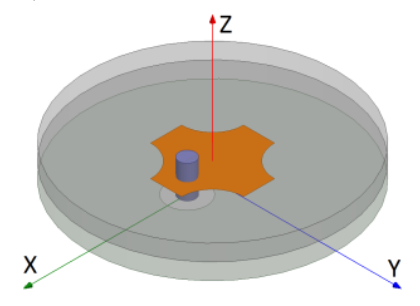

Fig. 8. A single element patch antenna with increased length of the central pin of the coaxial feed.

A simulated $S_{11}$ of such a design is shown in Fig. 9. From this figure we can see that the additional fifth resonance

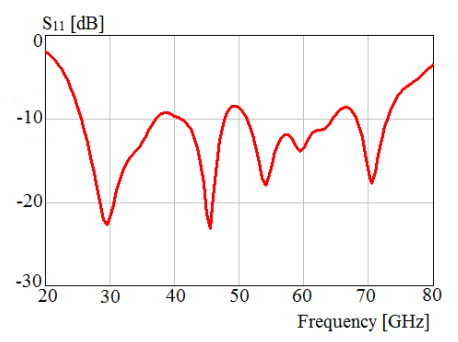

Fig. 9. $S_{11}$ of the patch antenna with increased central pin of the coaxial feed. appeared at the frequency of $71 \mathrm{GHz}$, and the working frequency band of the design was $25.5-73 \mathrm{GHz}$, but for frequencies of 39, 49 and $67 \mathrm{GHz}, \mathrm{S}_{11}$ was higher than $-10 \mathrm{~dB}$.

To match the design at these frequencies, we connected the increased pin of the coaxial feed with the second radiating element that had the same shape as the first radiating element, with dimensions $L_{2}=2.55 \mathrm{~mm}$ and $R_{2}=0.95 \mathrm{~mm}$. The modified stacked patch antenna design with electrical contact between both of the radiating patches was fabricated and measured (shown in Fig. 10).

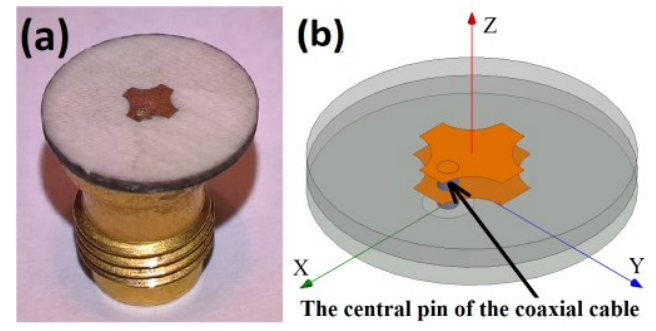

Fig. 10. (a) A photo of the fabricated stacked patch antenna with electrical contact between the central pin of a coaxial cable and both plates; and (b) a view of the modified stacked patch antenna.

Fig. 11 plots the measured and simulated $\mathrm{S}_{11}$ of the modified stacked patch antenna. From this figure we can see that the $S_{11}$ of the patch antenna was less than $-10 \mathrm{~dB}$ for frequencies of 23.9-72.2 GHz (the BW was $100.3 \%$ ). The influence of the size of ground plane on S11 of the antenna has been investigated. Simulated results verify that the ground plane does not affect the BW of the antenna, as long as the radius of the ground plane is larger than the length $L_{l}$ of the patch antenna. In addition, the BW was provided by five resonances, which corresponded to measured (simulated) frequencies of 27 (30), 43 (45), 51 (55), 63 (63) and 68 (67) GHz. Simulated distributions of normalized

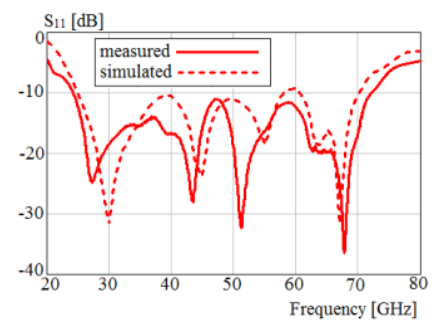

Fig. 11. $\mathrm{S}_{11}$ of the modified stacked patch antenna.

amplitude of surface electrical currents on the upper and bottom plates of the stacked patches for different resonance frequencies are shown in Fig. 12. From Fig. 12 we can see that for the frequency of $30 \mathrm{GHz}$, the maximum electrical current amplitude only existed on the edges of the bottom patch. Thus, the bottom plate was the main source of radiation for a frequency of $30 \mathrm{GHz}$. For higher resonance frequencies, both patches had a high amplitude of electrical currents on the edges, and thus both patches contributed to the overall radiation pattern. Fig. 12 shows that the current distributions were different for different frequencies, which indicates the excitation of different types of resonance modes.

Fig. 13 plots the measured and simulated radiation patterns and peak gain of the modified stacked patch antenna design. From this figure we can see that radiation patterns of the single 


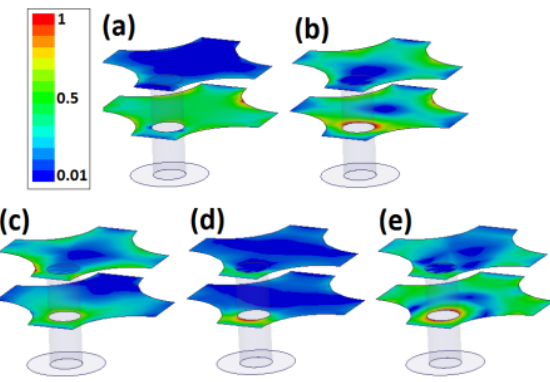

Fig. 12. Normalized current distribution on the metal plates of the modified stacked patch antenna for frequency of (a) $30 \mathrm{GHz}$, (b) $45 \mathrm{GHz}$, (c) $55 \mathrm{GHz}$, (d) $63 \mathrm{GHz}$, and (e) $67 \mathrm{GHz}$.

patch with a dielectric superstrate (Fig. $6[\mathrm{a}],[\mathrm{b}])$ and the stacked patch (Fig. 13 [a], [b]) have the same shape for a frequency of $30 \mathrm{GHz}$. This fact confirms the conclusion that the bottom plate creates the main contribution in radiation pattern for a frequency of $30 \mathrm{GHz}$. The measured peak gain and the simulated total efficiency of the modified stacked patch antenna (shown in Fig. 14) varies from 5.2 to $8.2 \mathrm{dBi}$ (a $3 \mathrm{~dB}$ variation) and from 0.73 to 0.96 respectively for the entire working frequency band.
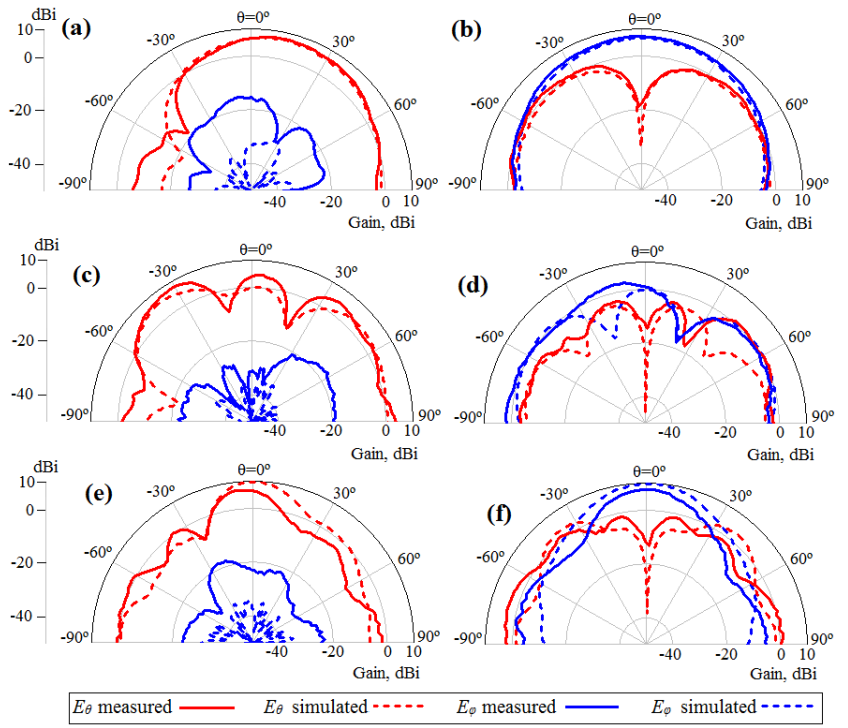

Fig. 13. Radiation patterns of the modified stacked patch antenna: (a) XZ plane, $30 \mathrm{GHz}$; (b) YZ-plane, $30 \mathrm{GHz}$; (c) XZ-plane, $50 \mathrm{GHz}$; (d) YZ-plane, $50 \mathrm{GHz}$; (e) XZ-plane, $70 \mathrm{GHz}$; (f) YZ-plane, $70 \mathrm{GHz}$.

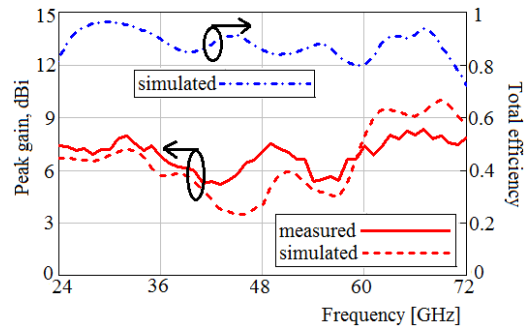

Fig. 14. Peak gain and total efficiency of the modified stacked patch antenna.

\section{CONCLUSION}

Thus, a physically connected stacked patch antenna design with radiating patch plates of a square shape with angled circular cutouts provides $100.3 \% \mathrm{BW}$ and peak gain of more than $5 \mathrm{dBi}$ inside the working band.

\section{REFERENCES}

[1] "5G spectrum recommendations," 5G Amer., Bellevue, WA, USA, White Paper, Apr. $2017 . \quad$ [Online]. Available: http://www.5gamericas.org/files/9114/9324/1786/5GA_5G_Spectrum_R ecommendations 2017 FINAL.pdf

[2] R. C. Daniels, J. N. Murdock, T. S. Rappaport, R. W. Heath, "60 GHz Wireless: Up Close and Personal," IEEE Microwave Magazine, vol. 11, no. 7, pp. 44-50, Dec. 2010.

[3] G. M. Galvan-Tejada, M. A. Peyrot-Solis, H. J. Aguilar, Ultra Wideband Antennas: Design, Methodologies, and Performance. Boca Raton, FL: CRC Press, 2016.

[4] J. R. James and P. S. Hall, Handbook of Microstrip Antennas. London, UK: Peter Peregrinus Ltd., 1989.

[5] S. D. Targonski, R. B. Waterhouse, and D. M. Pozar, "Design of WideBand Aperture-Stacked Patch Microstrip Antennas," IEEE Trans. Antennas Propag., vol. 46, no. 9, pp. 1245-1251, Sept. 1998.

[6] P. K. Singhal, B. Dhaniram, and S. Banerjee, "A Stacked Square Patch Slotted Broadband Microstrip Antenna," Journal of Microwaves and Optoelectronics, vol. 3, no. 2, pp. 60-66, Aug. 2003.

[7] M. A. Matin, B. S. Sharif, and C. C. Tsimenidis, "Probe Fed Stacked Patch Antenna for Wideband Applications," IEEE Trans. Antennas Propag., vol. 55, no. 8, pp. 2385-2388, Aug. 2007.

[8] A. A. Lotfi Neyestanak, "Ultra wideband rose leaf microstrip patch antenna," PIER, vol. 86, pp. 155-168, 2008.

[9] M. N. Shakib, M. T. Islam, N. Misran, "Stacked patch antenna with folded patch feed for ultra-wideband application," IET Microwaves, Antennas \& Propagation, vol. 4, no. 10, pp. 1456-1461, Oct. 2010.

[10] V. P. Sarin, M. S. Nishamol, D. Tony, C. K. Aanandan, P. Mohanan, and K. Vasudevan, "A Broadband L-Strip Fed Printed Microstrip Antenna," IEEE Trans. Antennas Propag., vol. 59, no. 1, pp. 281-284, Jan. 2011.

[11] H. Malekpoor and S. Jam, "Ultra-wideband shorted patch antennas fed by folded-patch with multi resonances," PIER, vol. 44, pp. 309-326, 2012.

[12] V. V. Golovin and Y. N. Tyschuk, "Multielement patch antenna array of operated polarization of Ku-band," in Proc. 9th Int. Conf. on Antenna Theory and Techniques (ICATT), Odessa, Ukraine, 2013, pp. 286-288.

[13] F. Zhu, S. Gao, A. T. S. Ho, R. A. Abd-Alhameed, C. H. See, T. W. C. Brown, J. Li, G. Wei, and J. Xu, "Ultra-Wideband Dual-Polarized Patch Antenna With Four Capacitively Coupled Feeds," IEEE Trans. Antennas Propag., vol. 62, no. 5, pp. 2440-2449, May 2014.

[14] G. K. Pandey, H. S. Singh, P. K. Bharti and M. K. Meshram, "Metamaterial-based UWB antenna," Electronics Letters, vol. 50, no. 18, pp. 1266-1268, Aug. 2014

[15] Y. Dai, B. Yuan, G. Luo, X. Zhang, "Ultra-wideband patch antenna with metamaterial structures," in Proc. IEEE 16th Int. Conf. on Communication Technology (ICCT), Hangzhou, China, 2015, pp. 403404

[16] K. Klionovski and A. Shamim, "Back Radiation Suppression through a Semitransparent Ground Plane for a Millimeter-Wave Patch Antenna," IEEE Trans. Antennas Propag., vol. 65, no. 8, pp. 3935-3941, Aug. 2017.

[17] K. Klionovski, "Broadband dual-band microstrip antenna [Широкополосная двухдиапазонная микрополосковая антенна]," RU Patent for the utility model 167296 U1, Dec. 27, 2016. [in Russian]

[18] N. G. Alexopoulos and D. R. Jackson, "Fundamental Superstrate (Cover) Effects on Printed Circuit Antennas," IEEE Trans. Antennas Propag., vol. 32, no. 8, pp. 807-816, Aug. 1984

[19] H. Attia and O. M. Ramahi, "EBG superstrate for gain and bandwidth enhancement of microstrip array antennas," in Proc. Antennas Propag. Soc. Int. Symp., San Diego, CA, 2008.

[20] K. L. Chung and S. Chaimool, "Broadside gain and bandwidth enhancement of microstrip patch antenna using a MNZ-metasurface," Microwave and Optical Technology Letters, vol. 54, no. 2, pp. 529-532, Feb. 2012

[21] V. Saidulu, K. Srinivasa Rao, P.V.D. Somasekhar Rao, "The Characteristics of Rectangular and Square Patch Antennas With Superstrate," Int. J. of Engineering Sciences \& Emerging Technologies, vol. 6, no. 3, pp. 298-307, Dec. 2013. 